\title{
Complementation of the hha mutation in Escherichia coli by the ymoA gene from Yersinia enterocolitica: dependence on the gene dosage
}

\author{
Carlos Balsalobre, Antonio Juárez, Cristina Madrid, Mercedes Mouriño, \\ Antonio Prenafeta and Francisco J. Muñoa
}

\begin{abstract}
Author for correspondence: Francisco J. Muñoa. Tel: +3493 4021492. Fax: + 34934110592.
e-mail:fmunoa@porthos.bio.ub.es
\end{abstract}

Universidad de Barcelona, Departamento de Microbiología, Avenida Diagonal, 645 Barcelona08028, Spain

\begin{abstract}
The Hha protein from Escherichia coli is highly similar $(82 \%)$ to the YmoA protein from Yersinia enterocolitica. Both are members of a new class of proteins that modulates gene expression, probably by influencing DNA topology. In this paper, complementation of the hha mutation in E. colf by the ymoA gene from $Y$. enterocolitica has been studied. We show that the ymoA gene complements one of the phenotypic properties of hha mutants (high level of haemolysin production when they carry the recombinant plasmid PANN202-312) when cloned in a medium-copy-number plasmid but not when carried in a low-copy-number plasmid. Western blot analysis of the expression of YmoA in E. coli rules out inefficient expression of the protein. Surprisingly, the hha gene itself fails to complement the hha mutation when cloned in a medium-copy-number vector and causes genetic rearrangements of the $E$. coli chromosome as a consequence of insertion sequences mobilization.
\end{abstract}

Keywords: $b h a$ gene, $y$ mo $A$ gene, gene complementation, gene dosage, insertion element mobilization

\section{INTRODUCTION}

The bha gene has been identified as modulating the expression of haemolysin in Escherichia coli (Godessart $e t$ al., 1988). Its product, the Hha protein, is an $8.6 \mathrm{kDa}$ protein that shows $82 \%$ similarity to the $\mathrm{YmoA}$ protein of Yersinia enterocolitica (De la Cruz et al., 1992), a temperature-dependent modulator of the expression of virulence factors in this micro-organism (Cornelis et al., 1991). Factors that alter the degree of DNA supercoiling mimic the effect of the bha mutation on the expression of haemolysin in cells harbouring the recombinant haemolytic plasmid pANN202-312. As bha mutants also show alterations in the degree of plasmid DNA supercoiling, it was suggested that the mechanism by which the Hha protein modulates gene expression is through changes of DNA topology (Carmona et al., 1993). Both $b h a$ and $y m o A$ mutants display a pleiotropic phenotype (Blanco et al., 1991; Cornelis et al., 1991; Nieto et al., 1987). It has been suggested that both proteins are members of the same class of proteins that modulates

Abbreviation: IS, insertion sequence(s). bacterial gene expression, probably by affecting DNA topology (De la Cruz et al., 1992; Mikulskis \& Cornelis, 1994).

Recently, complementation of the ymo $A$ mutation by the bha gene has been studied (Mikulskis \& Cornelis, 1994). The authors showed that some selection pressure occurred at the stage of introduction of the bba-gene-containing plasmid into $Y$. enterocolitica either by conjugation from $E$. coli or by electroporation. Transconjugants and transformants occurred at very low frequencies and carried mutations either in the promoter region or in the coding sequence of the bha gene (Mikulskis \& Cornelis, 1994). Despite the sequence alterations, the modified recombinant plasmids did complement the ymo $A$ mutation. The authors could also observe a significant mobilization of insertion sequences (IS) from the chromosome of the $E$. coli strain used as donor in the conjugation experiment. The authors interpreted this as being a consequence of the increased dosage of the $b b a$ gene, which was carried in a medium-copy-number plasmid.

In this paper, we have addressed the question of whether or not the ymo $A$ gene, cloned in vectors with different copy number, complements the bha mutation in $E$. coli. 


\section{METHODS}

Bacterial strains, plasmids and media. E. coli strains and plasmids are listed in Table 1. pLG338-30 is a $5 \mathrm{~kb}$, low-copynumber (one to five copies per cell) plasmid containing the replicon from plasmid pSC101. Plasmid pANN202-312 carries the blyC $A B D$ gene cluster from the low-copy-number haemolytic plasmid pHly152, and was previously described by Goebel \& Hedgepth (1982). Strain UBMY1 of Y. enterocolitica, used for amplification of the $y m o A$ gene, was isolated in a foodquality-control laboratory.

Bacterial cultures were grown in LB supplemented with antibiotics at the following concentrations $\left(\mathrm{mg} \mathrm{l}^{-1}\right)$ : ampicillin, 0.025 for plasmids derived from pLG338-30 and 0.1 for plasmids derived from pBR322; chloramphenicol, 0.05; and kanamycin, 0.025 .

Cloning of the ymoA and hha genes. Synthesis of the ymo $A$ gene was carried out by the PCR technique. A colony of the strain of $Y$. enterocolitica used in this study was resuspended in $100 \mu \mathrm{l}$ distilled water, $1 \mu \mathrm{l}$ of the suspension being used directly as template in the PCR reaction. Amplimers YMOA1 (5'-GGGATCCGAGCGTTTATTCAGACTTTTC-3') and YMOA2 (5'-GGTCGACCGTTGTGTGTCT'TAACCAGCG$\left.3^{\prime}\right)$ were designed according to the $y$ mo $A$ sequence published by Cornelis et al. (1991), except for the seven nucleotides on both $5^{\prime}$ ends that were included to generate targets for $B a m \mathrm{HI}$ (YMOA1) and SalI (YMOA2), thus allowing easy cloning after amplification. The $351 \mathrm{bp}$ product was then cloned into the pGEM-T vector system (Promega, A3600), its nucleotide composition being determined by DNA sequencing with Sequenase (United States Biochemical), and was finally cloned as a BamHI-SalI fragment into plasmids pLG338-30 and pBR322. Gene $b b a$ from $E$. coli was cloned by the same procedure described for $y m o$ A. Amplimers HHA1 (5'-GGGATCCAACCTCGCGATCAACCTCCAG-3') and HHA2 (5'-GGTCGAC'TTCATGGCGAAAAAGTATAAA-3') were designed according to the sequence published by Nieto et al. (1991). E. coli $5 \mathrm{~K}$ was used as template for amplification of the $b b a$ gene, which was then sequenced and cloned following the same procedure described for $y m o A$.

Haemolysin assay. Sheep erythrocytes $(6 \mathrm{ml})$ were washed several times with $0.9 \% \mathrm{NaCl}$ and resuspended in $130 \mathrm{ml}$ of the same saline solution to which $20 \mathrm{ml} 0.2 \mathrm{M} \mathrm{CaCl}_{2}$ was added; $1.2 \mathrm{ml}$ of this solution was then mixed with $200 \mu \mathrm{l}$ of the corresponding sample to be assayed, and incubated at $37^{\circ} \mathrm{C}$. At different times, the microfuge tubes were centrifuged for $30 \mathrm{~s}$, and the release of haemoglobin was measured by monitoring the increase in $A_{543}$ using a Shimadzu model UV-265FW spectrophotometer. To calculate the haemolytic units we used the following formula: units $=1000 \times A_{543}$ per $\mathrm{OD}_{600}$ unit $\mathrm{min}^{-1} \mathrm{ml}^{-1}\left(\mathrm{OD}_{600}\right.$ being used as a measure of culture density).

Haemolysin Western blot analysis. Samples were taken when cells entered the stationary phase $\left(\mathrm{OD}_{600}=1 \cdot 0\right)$. Upon centrifugation, $1 \mathrm{ml}$ supernatant samples were concentrated by acetone precipitation and used without further manipulation for the detection of HlyA by Western blot analysis as previously described by Nieto et al. (1991), using rabbit polyclonal antiserum raised against HlyA.

Hha- and YmoA-specific antibodies. A peptide that included the 17 amino-terminal residues of the Hha protein was synthesized and injected into rabbits as a conjugate with keyhole limpet haemocyanin by standard procedures. Testing the extracted serum allowed us to realize that it was able to recognize YmoA as well as Hha. Western blot analysis of the expression of Hha and YmoA was done by standard procedures.

\section{RESULTS}

\section{Amplification, sequencing and cloning of the ymoA gene from $Y$. enterocolitica and the $h$ ha gene from E. coli}

We amplified ymo $A$ with its own promoter from $Y$. enterocolitica chromosomal DNA. A single $0.35 \mathrm{~kb}$ DNA fragment was synthesized and its sequence was determined in both directions. The base composition of the amplified sequence turned out to be exactly as previously described by Cornelis et al. (1991). The ymo $A$ gene was then cloned with its own promoter into the BamHI-SalI sites of plasmids pLG338-30 and pBR322, forming plasmids pCB1Y and pCB2Y, respectively. The bba gene was also amplified, sequenced and cloned with its own promoter exactly as described for ymo $A$. A $0.57 \mathrm{~kb}$ fragment was the result of the amplification procedure. The nucleotide sequence of the fragment turned out to be as previously described by us (Nieto et al., 1991). Finally, the $b b a$ gene was cloned into the BamHI-Sall sites of plasmids pLG338-30 and pBR322, forming plasmids $\mathrm{pCB} 1 \mathrm{H}$ and $\mathrm{pCB} 2 \mathrm{H}$, respectively.

Table 1. E. coli strains and plasmids

\begin{tabular}{|c|c|c|}
\hline Strain/plasmid & Genotype/description & Source/reference \\
\hline \multicolumn{3}{|l|}{ Strains } \\
\hline $5 \mathrm{~K}$ & $\mathrm{~F}^{-}$bsdR bsdM rpsL thr thi leu lac $Z$ & Godessart et al. (1988) \\
\hline Hha3 & $5 \mathrm{~K} b b a:: \operatorname{Tn} 5 p b o A$ & Godessart et al. (1988) \\
\hline \multicolumn{3}{|l|}{ Plasmids } \\
\hline pANN202-312 & blyC Hly $A$ HlyB HlyD; $\mathrm{Cm}^{\mathrm{r}}$ & Goebel \& Hedgepth (1982) \\
\hline pSUP104-sac & $\mathrm{Cm}^{\mathrm{r}} \mathrm{Km}^{\mathrm{r}} ;$ sacB cassette & Simon et al. (1991) \\
\hline pLG338-30 & ori $_{\mathrm{PSC101}} ; \mathrm{Ap}^{\mathrm{r}}$ & Cunningham et al. (1993) \\
\hline pBR322 & $o r i_{\mathrm{pMB1}} ; \mathrm{Ap}^{\mathrm{r}} \mathrm{Tc}^{\mathrm{r}}$ & Bolívar et al. (1977) \\
\hline $\mathrm{pCB} 1 \mathrm{Y}$ & pLG338-30 + PCR-synthesized ymo $A$; Ap ${ }^{\mathrm{r}}$ & This study \\
\hline $\mathrm{pCB} 2 \mathrm{Y}$ & pBR322 + PCR-synthesized ymo $A ; \mathrm{Ap}^{\mathrm{r}}$ & This study \\
\hline $\mathrm{pCB} 1 \mathrm{H}$ & pLG338-30 + PCR-synthesized $b b a ; A p^{r}$ & This study \\
\hline $\mathrm{pCB} 2 \mathrm{H}$ & pBR322 + PCR-synthesized $b b a ; A^{\mathrm{r}}$ & This study \\
\hline
\end{tabular}


Table 2. Haemolytic phenotype on blood-agar plates of transformants obtained with recombinant plasmids carrying either $y m \circ A$ or hha

\begin{tabular}{|c|c|c|c|c|c|}
\hline Strain* & $\begin{array}{l}\text { Recombinant } \\
\text { plasmid }\end{array}$ & Replicon & $\begin{array}{c}\text { Copy } \\
\text { number }\end{array}$ & $\begin{array}{c}\text { Gene } \\
\text { cloned }\end{array}$ & $\begin{array}{c}\text { Haemolytic } \\
\text { haloes }\end{array}$ \\
\hline $5 \mathrm{~K}$ & None & & & & $\begin{array}{l}\text { Narrow (parental } \\
\text { phenotype) }\end{array}$ \\
\hline Hha3 & None & & & & $\begin{array}{l}\text { Large (mutant } \\
\text { phenotype) }\end{array}$ \\
\hline Hha3 & pCB1Y & pLG330 & Low & $y m o A$ & Large \\
\hline Hha3 & $\mathrm{pCB} 1 \mathrm{H}$ & pLG330 & Low & $b b a$ & Narrow \\
\hline Hha3 & pCB2Y & pBR322 & Medium & $y m o A$ & Narrow \\
\hline Hha3 & $\mathrm{pCB} 2 \mathrm{H}$ & pBR322 & Medium & $b b a$ & Variablet \\
\hline
\end{tabular}

* All strains also contained the haemolytic plasmid pANN202-312.

$\dagger$ The colonies were basically poorly haemolytic but displayed heterogeneity in the size of the individual haloes.

\section{Transformation of $E$. coli with the recombinant plasmids harbouring either hha or ymoA}

Plasmids pCB1Y, pCB2Y, $\mathrm{pCB} 1 \mathrm{H}$ and $\mathrm{pCB} 2 \mathrm{H}$ were transformed into $E$. coli strain Hha3(pANN202-312). This strain forms large haemolytic haloes on blood-agar plates (highly haemolytic phenotype) as a consequence of the bha mutation. Transformants were plated on blood-agar plates containing the relevant selective agents for the plasmids and $\operatorname{Tn} 5$ and incubated for $24 \mathrm{~h}$. Observation of the haemolytic haloes obtained for each recombinant plasmid gave an initial picture of the haemolytic phenotype of the recombinant clones (Table 2). Whereas all the transformants obtained with plasmid pCB1Y showed a highly haemolytic phenotype, transformants obtained with plasmid $\mathrm{pCB} 1 \mathrm{H}$ showed a haemolytic phenotype similar to that of the parental $5 \mathrm{~K}$ (pANN202-312) strain (narrow haemolytic haloes). As in both cases the colonies were homogeneous in size and in haemolytic phenotype, only one colony from each transformation was purified to carry out the complementation analysis. All transformants obtained with plasmid $\mathrm{pCB} 2 \mathrm{Y}$ showed the parental haemolytic phenotype. One colony was purified to carry out the complementation analysis. Finally, transformants obtained with $\mathrm{pCB} 2 \mathrm{H}$ gave rise to colonies that were basically poorly haemolytic but which displayed heterogeneity in size. Haloes were also heterogeneously sized. Two colonies, Hha3(pANN202-312)(pCB2H)A and Hha3(pANN202-312)(pCB2H)B, were studied. No differences in the transformation frequencies were apparent for any of the plasmids used.

\section{Complementation of the hha mutation by the ymoA and hha genes}

Complementation analysis was carried out by measuring the external haemolytic activity (active haemolysin) during growth and also by detecting the HlyA polypeptide in the external medium by Western blot analysis of the supernatant of the cultures (total secreted haemolysin) of the selected transformants, strain Hha3(pANN202-312) and the parental strain $5 \mathrm{~K}$ (pANN202-312). The results obtained are shown in Fig. 1. Differences in growth kinetics were only detected for the strains carrying plasmids $\mathrm{pCB} 2 \mathrm{HA}$ and $\mathrm{pCB} 2 \mathrm{HB}$, which respectively reached a final $O_{600}$ of 1.01 and $2 \mathrm{~h}$ after the other strains studied (data not shown). As can be seen, strains carrying the $b b a$ gene cloned on the low-copy-number plasmid $\mathrm{pCB} 1 \mathrm{H}$ and the $y m o A$ gene cloned on the medium-copy-number plasmid $\mathrm{pCB} 2 \mathrm{Y}$ clearly complemented the bha mutation and displayed haemolysin production kinetics and final levels of total and active haemolysin similar to those exhibited by the parental strain $5 \mathrm{~K}$ (pANN212-312). On the other hand, the ymo $A$ gene cloned in PCB1Y did not complement the bha mutation at all. Strain Hha-3(pANN202-312)(pCB1Y) showed similar kinetics and levels of haemolysin expression to those shown by strain Hha-3(pANN202-312). Finally, the two strains harbouring the $b h a$ gene cloned in pCB2H did not complement the haemolytic phenotype, with both haemolysin production kinetics and final levels being different to those of the $5 \mathrm{~K}$ (pANN302-312) strain.

Recent data reported by Mikulskis \& Cornelis (1994) indicated that the $b b a$ gene induced IS jumping and other genetic rearrangements in the E. coli genome when cloned in a pACYC184 plasmid derivative. The recombinant plasmid itself was also affected and presented alterations in the sequence of the cloned bba gene. Thus, following the complementation analysis, we decided to test if the sequences of the $b h a$ and $y m o A$ genes cloned in plasmids $\mathrm{pCB} 1 \mathrm{H}, \mathrm{pCB} 1 \mathrm{Y}, \mathrm{pCB} 2 \mathrm{H}$ and $\mathrm{pCB} 2 \mathrm{Y}$ had remained unaltered. With this aim, recombinant plasmids were isolated from strains Hha3(pCB1Y), Hha3(pCB2Y), Hha3(pCB1H), Hha3(pCB2H)A and Hha3(pCB2H)B, digested with BamHI-SalI and electrophoretically analysed. No differences in size were detected for any of the five plasmids analysed, either in the insert or in the vector sequences. Thus, none of them contained any IS element. Four inserts [the one obtained from strain Hha3(pCB2H)B was not used further] were then purified from the gel and cloned again into new vector molecules 
(a)

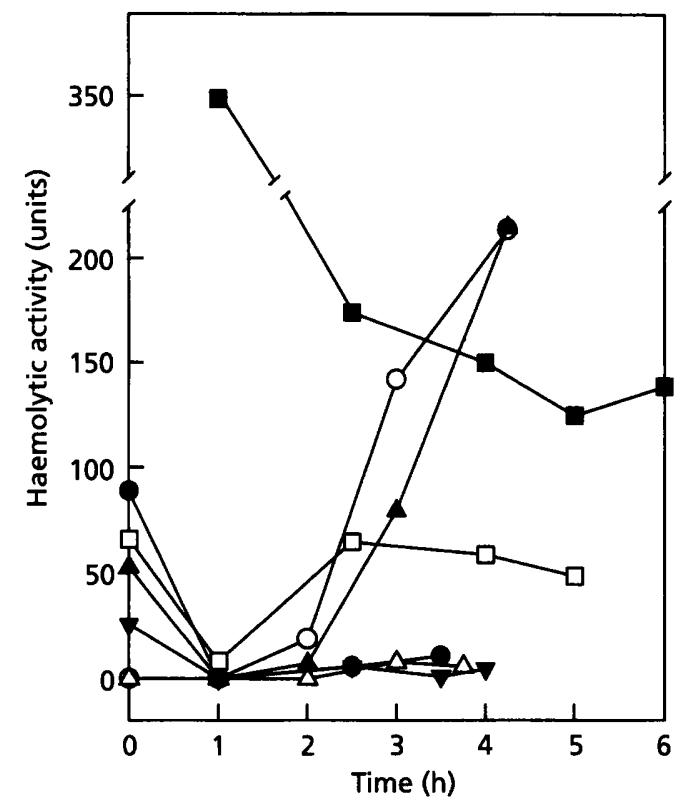

(b)

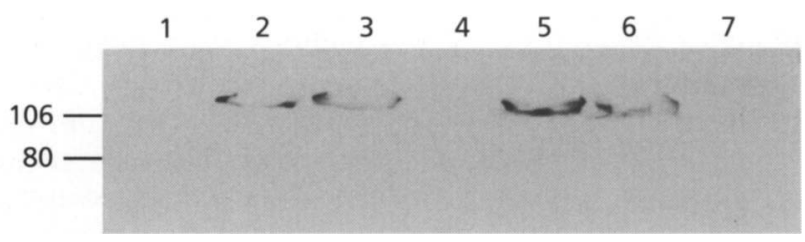

and total haemolysin. The values obtained were the same as those already observed for the recombinant plasmids initially obtained (results not shown). The fact that a fragment containing either the bha or ymo $A$ gene from plasmids that did not complement the bha mutation could then complement it when cloned in a different plasmid, showed that the $b b a$ and $y m o A$ genes were functional and that modifications of their sequences were not at the origin of the differences in haemolysin production observed when those genes were cloned into two differentcopy-number vectors.

As plasmid $\mathrm{PCB} 2 \mathrm{Y}$ complemented the bha mutation but plasmid pCB1Y did not, we decided to test if the ymo $A$ gene was poorly expressed in E. coli, only a high-gene dosage rendering sufficient levels of the YmoA protein to complement the bha mutation. To test this, we monitored the production of Hha and YmoA proteins by Western blot analysis of cell extracts obtained from strains harbouring the corresponding recombinant plasmids. Cell extracts from clones $\mathrm{pCB} 1 \mathrm{Y}$ and $\mathrm{PCB} 1 \mathrm{H}$ showed similar amounts of $\mathrm{YmoA}$ and Hha, respectively, as also did clones harbouring pCB2Y and $\mathrm{pCB} 2 \mathrm{H}$ (data not show), thus indicating that $\mathrm{YmoA}$ was properly expressed in $E$. coli.

\section{Mobilization of IS in the $E$. coli strains containing the recombinant plasmids}

A surprising result from this study was that the $0.57 \mathrm{~kb}$ DNA fragment containing the bba gene failed to complement the highly haemolytic phenotype of strain Hha3(pANN202-312) when cloned in plasmid pBR322. The transformants obtained with plasmid pCB2H showed heterogeneity on blood-agar plates and the two purified isolates displayed haemolysin levels and production kinetics different from each other and from those shown by the control strain Hha3(pANN202-312). Considering the previously reported results of Mikulskis \& Cornelis (1994) on the effect of a high-gene dosage of $b h a$ on IS element mobilization, we decided to test if, in our model, different levels of Hha and YmoA proteins could also account for IS mobilization. To do this, an IS element 'trap', a sacB-gene-containing plasmid, was used. E. coli cells containing the Bacillus subtilis sacB gene will not grow in medium containing $5 \%(\mathrm{w} / \mathrm{v})$ sucrose unless inactivation of the $\operatorname{sac} B$ gene occurs. With this aim, strain Hha3(pSUP104-sac) was transformed with the same plasmids used in the complementation studies. Immediately after transformation, five colonies from each experiment were resuspended in liquid medium and grown overnight. Aliquots of each culture were plated in parallel on sucrose-containing and non-sucrose-containing agar. Table 3 shows the number of sucrose-resistant mutants among $10^{8}$ cells obtained for each culture. Significant differences were only detected for the clones containing the pBR322-related plasmids. Clones containing plasmid pCB2H clearly rendered higher numbers of colonies growing on sucrose plates than the control strain containing plasmid pBR322 and the strain containing the cloned $y m o A$ gene. No significant differences were detec- 
Table 3. Influence of hha and ymoA gene dosage on transposition mutations: numbers of sucrose-resistant mutants among $10^{8}$ cells in five different clones

\begin{tabular}{|lrrrrrrr|}
\hline Strain & \multicolumn{4}{c}{ Number of mutants } & \multicolumn{2}{c|}{$\begin{array}{c}\text { Geometric } \\
\text { mean }\end{array}$} \\
\cline { 2 - 6 } & Clone 1 & Clone 2 & Clone 3 & Clone 4 & Clone 5 & \\
\hline Hha3(pBR322) & 53 & 52 & 245 & 100 & 436 & 177 \\
Hha3(pCB2H) & 894 & 1083 & 603 & 578 & 357 & 703 \\
Hha3(pCB2Y) & 18 & 68 & 36 & 21 & 54 & 39 \\
Hha3(pLG338-30) & 25 & 19 & 23 & 93 & 17 & 35 \\
Hha3(pCB1H) & 10 & 123 & 12 & 27 & 32 & 41 \\
Hha3(pCB1Y) & 34 & 3 & 98 & 56 & 41 & 46 \\
\hline
\end{tabular}

ted among the strains containing pLG338-30-related plasmids. Because $s a c B$ inactivation could be due not only to IS element transposition but also to deletions or point mutations, plasmid DNA from 10 clones of each type was extracted and electrophoretically analysed. Plasmids were considered to contain an IS element if their size was bigger than the original plasmid pSUP104-sac, a deletion if they were smaller, or a point mutation if no differences were detected (Simon et al., 1991). The number of presumed IS-containing plasmids detected for $\mathrm{pCB} 2 \mathrm{H}$, $\mathrm{pCB} 2 \mathrm{Y}$ and $\mathrm{pBR} 322$ was eight, seven and seven, respectively. As the number of resistant clones that contained IS insertions was similar, it is apparent that plasmid pCB2H enhances the frequency of transposition events. This effect, which was not observed when the gene was cloned in a low-copy-number plasmid such as pLG33830 , could be responsible for the heterogeneous haemolytic phenotype displayed on blood-agar plates by clones harbouring plasmid $\mathrm{pCB} 2 \mathrm{H}$. It could also account for the non-complementing haemolytic phenotype described for the E. coli strains Hha3(pANN202-312)(pCB2H)A and Hha3(pANN202-312)(pCB2H)B. On the other hand, strains containing ymo $A$ either on a pBR322 derivative or on a pLG338-30 derivative showed no apparent difference in IS mobilization when compared with the control strain carrying only the vector.

\section{DISCUSSION}

Mikulskis \& Cornelis (1994) reported complementation of the ymo $A$ mutation in $Y$. enterocolitica by the bha gene of E. coli. Nevertheless, complementation was only accomplished when the recombinant plasmids harbouring the bba gene contained mutations either in the promoter region of $b b a$ or in the $b b a$ gene coding region. This was interpreted as the Hha protein being present at levels toxic for $Y$. enterocolitica, thus selecting for mutations which reduced tha expression or modified it, clones harbouring such modified plasmids being viable. In this study, we show that introduction of the ymo $A$ gene in $E$. coli, either in low- or in medium-copy-number plasmids, did not result in the selection of clones containing a modified ymo $A$ gene. These results agree with those reported by Mikulskis \& Cornelis (1994), which also indicated that E. coli is more tolerant to bha or ymo $A$ than $Y$. enterocolitica, as both genes could be cloned and manipulated in the former host without accumulation of mutations. Nevertheless, $y$ mo $A$ complements the effect of the $b b a$ mutation on haemolysin expression only when cloned in the pBR322 derivative and not when plasmid pLG338-30 was used as vector. There are at least two possible explanations for these results. One of them could rely on the differences between proteins YmoA and Hha. Despite the $82 \%$ similarity that they exhibit, they are different in size. Both differences in size and in the amino acid sequence may account for an inefficient function of YmoA in E. coli, it only being able to substitute for Hha when overexpressed. Another possible explanation could rely on the fact that $y m o A$ was cloned in $E$. coli under the control of its own promoter region, which would not necessarily be efficiently recognized by the transcriptional machinery of $E$. coli. Related to that, we should point out that Western blot analysis of the expression of the $\mathrm{YmoA}$ and Hha proteins in E. coli rules out an inefficient expression of YmoA and reinforces the hypothesis that structural differences between Hha and YmoA may account for the inefficiency in complementing the $b b a$ allele.

Usually, vectors derived from ColE1 or from pMB1, such as pBR322 itself, are present at 15-20 copies per cell in $E$. coli and are said to be medium- or even low-copy-number. However, several authors have already pointed out that their copy number may be considered too high when they are used for cloning prokaryotic regulatory or membrane protein genes (Wang \& Kushner, 1991; Claverie-Martín et al., 1989; Spratt et al., 1980) or viral genomes (Cunningham et al., 1993) in E. coli. Here we show that the $0.57 \mathrm{~kb}$ DNA fragment containing the bba gene is responsible for an increase in genetic instability as a result of IS mobilization from the $E$. coli genome when cloned in a medium-copy-number but not in a low-copy-number vector. This observation was also reported by Mikulskis \& Cornelis (1994). We hypothesize that IS mobilization could be at the origin of the heterogeneous phenotype observed on blood-agar plates for the clones harbouring plasmid $\mathrm{pCB} 2 \mathrm{H}$. It could also explain why strains Hha3(pCB2H)A and Hha3(pCB2H)B, which contained this plasmid, exhibited a reduced growth rate in liquid culture compared to all other strains and showed aberrant haemolytic phenotypes when the complementation analysis was carried out. Finally, transposition of IS elements in 
strains harbouring plasmid pCB2H could also indicate that Hha may have a role in IS stability in the E. coli genome, but this point must be studied further.

As changes in DNA topology may influence the expression of several different genes and thus affect the physiology of the bacterial cell in very different ways, one can recommend special care in the choice of the appropriate cloning vector when a protein that probably influences DNA topology, like Hha, is studied. A similar observation was made when the $\operatorname{ssm} Z$ gene coding for the histone-like protein $\mathrm{H}-\mathrm{NS}$ was cloned in a ColE1 derivative vector and used for complementation analysis. The gene accumulated mutations at high frequency, probably selected to down-regulate its expression or the activity of the protein (Hulton et al., 1990). According to our results, cloning this class of proteins only into medium-copy-number plasmids like pBR322 is not an appropriate procedure for carrying out genetic complementation analysis, although it can help to obtain some additional information. Overproduction of proteins influencing DNA topology can be of interest, as it has been shown here and by some other authors (Spurio et al., 1992). This is also the case in a study where the authors searched for genes that circumvented the export-defective phenotypes of sec mutations when cloned into a multicopy plasmid derived from pBR322 (Ueguchi \& Ito, 1992). One of the clones that was active in suppression contained the gene for the histone-like protein $\mathrm{H}$-NS, which had never been described as influencing secretion in $E$. coli, and, according to the authors, the study described a novel phenotype of H-NS.

\section{ACKNOWLEDGEMENTS}

The authors thank Professor David Andreu from the Departament de Química Orgánica for the synthesis of the peptide used to obtain the Hha antibodies, Professor Drew Lichtenstein for the gift of the plasmid pLG338-30, and Dr M ${ }^{a}$ Dolors Ferré from the Laboratori Municipal de Barcelona for providing the $Y$. enterocolitica strain UBMY1. This work was supported by the CICYT, grant PB91-0561. C. B., M. M. and A.P. were recipients of an FI fellowship from the Generalitat de Catalunya.

\section{REFERENCES}

Blanco, A., Juárez, A. \& Pastor, F. I. J. (1991). Overproduction of a Clostridium cellulolyticum endoglucanase by mutant strains of Escherichia coli. FEMS Microbiol Lett 81, 221-226.

Bolivar, F., Rodriguez, R. L., Green, P. J., Betlach, M. C., Heyneker, H. L., Boyer, H. W., Crosa, J. H. \& Falkow, S. (1977). Construction and characterization of new cloning vehicles. II. A multipurpose cloning system. Gene 2, 95-113.

Carmona, M., Balsalobre, C., Muñoa, F., Mouriño, M., Jubete, Y., De la Cruz, F. \& Juárez, A. (1993). Escherichia coli bha mutants, DNA supercoiling and expression of the haemolysin genes from the recombinant plasmid pANN202-312. Mol Microbiol 9, 1011-1018.
Claverie-Martín, F., Diaz-Torres, M. R., Yancey, S. D. \& Kushner, S. K. (1989). Cloning of the altered mRNA stability (ams) gene of Eschericbia coli K-12. J Bacteriol 171, 5479-5486.

Cornelis, G. R., Sluiters, C., Delor, I., Gelb, D., Kaninga, K., Lambert de Rouvroit, C., Sory, M. P., Vanooteghem, J. C. \& Michaelis, T. (1991). ymo $A$, a Yersinia enterocolitica chromosomal gene modulating the expression of virulence functions. Mol Microbiol 5, 1023-1034.

Cunningham, T. P., Montelaro, R. C. \& Rushlow, K. E. (1993). Lentivirus envelope sequences and proviral genomes are stabilized in Escherichia coli when cloned in low-copy-number plasmid vectors. Gene 9, 93-98.

De la Cruz, F., Carmona, M. \& Juárez, A. (1992). The Hha protein from Escherichia coli is highly homologous to the YmoA protein from Yersinia enterocolitica. Mol Microbiol 6, 3451-3452.

Godessart, N., Muñoa, F. J., Regué, M. \& Juárez, A. (1988). Chromosomal mutations that increase the production of a plasmidencoded haemolysin in Escherichia coli. J Gen Microbiol 134, 2779-2787.

Goebel, W. \& Hedgepth, J. (1982). Cloning and functional characterization of the plasmid-encoded haemolysin determinant of Escherichia coli. J Bacteriol 151, 1290-1298.

Hulton, C. S. J., Seirafi, A., Hinton, J. C. D., Sidebotham, J. M., Waddell, L., Pavvit, G. D., Owen-Hughes, T., Spassky, A., Buc, H. \& Higgins, C. F. (1990). Histone-like protein H1 (H-NS), DNA supercoiling and gene expression in bacteria. Cell 63, 631-642.

Mikulskis, A. V. \& Cornelis, G. R. (1994). A new class of proteins regulating gene expression in enterobacteria. Mol Microbiol 11, $77-86$.

Nieto, J. M., Tomás, J. \& Juárez, A. (1987). Secretion of an Aeromonas bydrophila aerolysin by a mutant strain of Escherichia coli. FEMS Microbiol Lett 48, 413-417.

Nieto, J. M., Carmona, M., Bolland, S., Jubete, Y., De la Cruz, F. \& Juárez, A. (1991). The bha gene modulates haemolysin expression in Escherichia coli. Mol Microbiol 5, 1285-1293.

Simon, R., Høtte, B., Klauke, B. \& Kosier, B. (1991). Isolation and characterization of insertion sequence elements from gram-negative bacteria by using new broad-host-range, positive selection vectors. $J$ Bacteriol 173, 1502-1508.

Spratt, B. G., Boyd, A. \& Stoker, N. (1980). Defective and plaqueforming lambda transducing bacteriophage carrying penicillinbinding protein-cell shape genes: genetic and physical mapping and identification of gene products from the lip-dac $A$-rod $A-p b p A$-leuS region of the Escherichia coli chromosome. J Bacteriol 143, 569-581.

Spurio, R., Durrenberger, M., Falconi, M., La Teana, A., Pon, C. L. \& Gualerzi, C. O. (1992). Lethal overproduction of the Escherichia coli nucleoid protein H-NS: ultramicroscopic and molecular autopsy. Mol Gen Genet 231, 201-211.

Ueguchi, C. \& Ito, K. (1992). Multicopy suppression: an approach to understanding intracellular functioning of the protein export system. J Bacteriol 174, 1454-1461.

Wang, R. F. \& Kushner, S. R. (1991). Construction of versatile lowcopy-number vectors for cloning, sequencing and gene expression in Eschericbia coli. Gene 100, 195-199.

Received 14 November 1995; revised 2 February 1996; accepted 14 February 1996. 